\title{
Clinical Significance of Pulmonary Function Tests in Long-Term Survivors after Myeloablative Allogeneic Hematopoietic Stem Cell Transplantation
}

\author{
Kenji Matsumoto $^{1}$, Satomi Ito ${ }^{2}$, Wataru Yamamoto $^{1}$, Eriko Ogusa $^{1}$, Atsuo Maruta ${ }^{1}$, \\ Yoshiaki Ishigatsubo $^{2}$, Heiwa Kanamori ${ }^{1}$ \\ ${ }^{1}$ Department of Hematology, Kanagawa Cancer Center, Yokohama, Japan; ${ }^{2}$ Department Internal Medicine and Clinical Immunology, \\ Yokohama City University Graduate School of Medicine, Yokohama, Japan. \\ Email: matsumotok@kcch.jp
}

Received December $17^{\text {th }}, 2012$; revised January $18^{\text {th }}, 2013$; accepted February $3^{\text {rd }}, 2013$

\begin{abstract}
We retrospectively assessed long-term pulmonary function in adults surviving for $\geq 5$ years after myeloablative allogeneic hematopoietic stem cell transplantation and identified risk factors for late-onset noninfectious pulmonary complications. Among 174 patients undergoing transplantation for hematologic malignancies between May 1994 and December 2004, 81 long-term survivors were evaluated. Pulmonary function tests (PFTs) were performed before conditioning, 3 months and 1 year after transplantation, and then annually. Eight patients $(10 \%)$ had abnormal pulmonary function before transplantation, but this was not associated with late changes in PFTs. Patients with chronic graft-versus-host disease (GVHD) showed a significant decline of lung function after 3 years when compared with patients without chronic GVHD. Abnormal pretransplantation lung function was associated with pulmonary chronic GVHD according to National Institutes of Health criteria (score $0, n=58$; score $1, n=14$; score 2, $n=6$; score 3, $n=3$ ). Five patients with late-onset noninfectious pulmonary complications showed a decline of lung function at 1 year after transplantation. Only chronic GVHD was significantly related to late-onset noninfectious pulmonary complications. In conclusion, abnormal lung function before transplantation may be associated with a decline in pulmonary function within 1 year after transplantation, but late-onset noninfectious pulmonary complications could not be predicted from pretransplantation lung function.
\end{abstract}

Keywords: Long-Term Survivor; Pulmonary Function Tests; Late-Onset Noninfectious Pulmonary Complications; Myeloablative Allogeneic Stem Cell Transplantation

\section{Introduction}

Allogeneic hematopoietic stem cell transplantation (HSCT) is a potentially curative procedure for patients with hematologic malignancies. Despite of improvements in supportive care, the morbidity and mortality associated with this procedure remains a major problem. For example, pulmonary complications occur in $40 \%$ to $-60 \%$ of HSCT patients and account for $10 \%$ to $40 \%$ of transplant-related deaths [1]. In particular, late-onset noninfectious pulmonary complications, such as bronchiolitis obliterans (BO), BO-organizing pneumonia and interstitial pneumonia occurring from 3 months after transplanttation are thought to be linked to chronic graft-versushost disease (GVHD) and can result in decreased quality of life or even death [2-4].

Frequent monitoring lung function before and after transplantation is needed to predict or detect early pul- monary complications [5-10], but the long-term clinical significance of such data is not clear. Thus, the goal of the present study was to perform a retrospective analysis of the relationship between pretransplantation lung function, posttransplantation lung function, and late-onset noninfectious pulmonary complications in adult patients surviving for $\geq 5$ years after myeloablative HSCT.

\section{Patient and Methods}

\subsection{Subjects}

Among 174 patients who underwent transplantation with uniform myeloablative conditioning for hematologic malignancies between May 1994 and December 2004 at Kanagawa Cancer Center, there were 94 long-term survivors with a minimum 5 years of follow-up after transplantation. Among them, seven patients had undergone re-transplantation for relapse or engraftment failure with- 
in 5 years of their initial HSCT, and they were excluded from this study. All patients gave written informed consent, and the study was approved by the Institutional Review Board of our hospital.

\subsection{Transplantation Procedure}

All patients received pretransplantation conditioning with thiotepa ( $200 \mathrm{mg} / \mathrm{m}^{2}$ for 2 days), cyclophosphamide (2250 $\mathrm{mg} / \mathrm{m}^{2}$ for 2 days in patients age $\leq 40$ years or 2000 $\mathrm{mg} / \mathrm{m}^{2}$ for 2 days in those age $>40$ years), and total body irradiation (12.5 Gy in five fractions) [11]. For prevention of GVHD, patients received cyclosporine A (3 $\mathrm{mg} / \mathrm{kg} /$ day $)$ or tacrolimus $(0.03 \mathrm{mg} / \mathrm{kg})$ together with short-term methotrexate(MTX), which was given intravenously at a dose of $15 \mathrm{mg} / \mathrm{m}^{2}$ on day 1 and $10 \mathrm{mg} / \mathrm{m}^{2}$ on days 3 and 6. From February 2000, the MTX doses were reduced to $10 \mathrm{mg} / \mathrm{m}^{2}$ on day 1 and $7 \mathrm{mg} / \mathrm{m}^{2}$ on days 3 and 6. All patients were isolated in a laminar air flow room and were treated with antibiotics and antifungal agents for gastrointestinal decontamination until engraftment was achieved. Administration of lenograstim $(5 \mu \mathrm{g} / \mathrm{kg} /$ day, civ) was initiated on day 1 after transplanttation and was continued until recovery of the neutrophil count.

\subsection{Pulmonary Function Tests}

All patients were followed at the Kanagawa Cancer Center. Pulmonary function tests were part of the routine protocol and were performed before preconditioning, at 3 months and 1 year after transplantation, and annually thereafter if possible. Forced vital capacity (FVC), forced expiratory volume in one second (FEV1), and the FEV1/ FVC ratio were determined to measure ventilatory capacity, while the vital capacity (VC) was used to measure lung volume. The diffusion capacity of carbon monoxide (DLCO) was determined by the carbon monoxide single-breath technique with correction for the hemoglobin concentration. VC, FEV1, and DLCO were expressed as a percentage of the predicted values for healthy controls.

\subsection{Definitions}

Abnormal lung function was defined as less than $80 \%$ of the predicted value for VC, FEV1, or DLCO. Pulmonary changes due to chronic GVHD were assessed by National Institutes of Health (NIH) consensus criteria [12]. According to the criteria, pulmonary scoring was based on clinical findings and pulmonary function tests scale. Scoring using the Lung Function Score (LFS) was preferred, but if DLCO is not available, grading using FEV1 was used. The percent predicted FEV1 and DLCO were converted to a numeric score as follows: $>80 \%=1 ; 70 \%$ $-79 \%=2 ; 60 \%-69 \%=3 ; 50 \%-59 \%=4 ; 40 \%-49 \%=$
$5 ;<40 \%=6$. LFS $=$ FEV1 score + DLCO score. At the time of transplantation, patients were divided into standard-risk and high-risk groups. Standard-risk patients included those with acute leukemia in complete remission (CR), chronic myelogenous leukemia (CML) in the chronic phase, and myelodysplastic syndrome (MDS) with refractory anemia or CR after chemotherapy. Highrisk patients included those who had acute leukemia without remission, MDS in the phase of refractory anemia with excess blasts (RAEB), and CML in the accelerated or blastic phase. Smokers were defined as patients who regularly smoked $\geq 1$ pack/day within 12 months before the onset of disease for a minimum of 2 years. BO was diagnosed based on a combination of FEV1 less than $75 \%$ of the predicted value, FEV1/FVC ratio less than $70 \%$, and evidence of air trapping or small air way thickening or bronchiectasis on high-resolution chest computed tomography (CT). Interstitial pneumonia (IP) was diagnosed on the basis of bilateral diffuse parenchymal interstitial/alveolar infiltrates on chest X-ray films and/or CT scans with associated hypoxemia $\left(\mathrm{PaO}_{2}\right.$ $<70 \mathrm{mmHg}$ and $\mathrm{A}-\mathrm{aDO}_{2}>20 \mathrm{mmHg}$ ). Both diagnoses were only made in patients without infections. Acute and chronic GVHD were diagnosed and graded according to published criteria $[13,14]$.

\subsection{Statistical Analysis}

Comparison of categorical variables was done by the chi-square test or Fisher's exact test, while comparison of continuous variables was performed with Student's $t$-test (two-sided). Patients with or without late-onset noninfectious pulmonary complications were compared on the basis of various factors before and after transplantation. A $\mathrm{p}$ value $<0.05$ was considered to indicate statistical significance. Data were analyzed as of March 31, 2010.

\section{Results}

\subsection{Patient Characteristics and Outcome}

Among 87 patients who survived beyond 5 years after a single HSCT procedure, six patients were excluded because of the lack of pretransplant pulmonary function data. The clinical characteristics of the remaining 81 patients are shown in Table 1. The median follow-up period was 9.3 years (range: 5.1 - 15.6 years), and the median age at transplantation was 38 years (range: $16-53$ years). Twenty-three patients had a history of smoking before the onset of hematologic disease. Busulfan had previously been administered to three of 19 patients with CML. Twenty patients (25\%) developed grade II-IV acute GVHD, and 40 patients (49\%) had chronic GVHD (limited in 18 patients, and extensive in 22 patients) among the long-term survivors. Five patients $(6 \%)$ died 
Table 1. Patient characteristics.

\begin{tabular}{|c|c|c|c|c|c|}
\hline Characteristcs & $\mathrm{n}$ & Pulmonary chronic GVHD ${ }^{\#}(\mathrm{n})$ & P value & LONIPCs (n) & P value \\
\hline Number & 81 & 23 & & 5 & \\
\hline \multicolumn{6}{|l|}{ Age at transplantation } \\
\hline$<38$ y & 38 & 12 & \multirow{2}{*}{0.55} & 3 & \multirow{2}{*}{0.66} \\
\hline $38 \mathrm{y}$ & 43 & 11 & & 2 & \\
\hline \multicolumn{6}{|l|}{ Gender } \\
\hline Male & 49 & 13 & \multirow{2}{*}{0.58} & 1 & \multirow{2}{*}{0.08} \\
\hline Female & 32 & 10 & & 4 & \\
\hline \multicolumn{6}{|l|}{ Diagnosis } \\
\hline Acute myelogenous leukemia & 30 & 8 & \multirow{4}{*}{0.86} & 1 & \multirow{4}{*}{0.08} \\
\hline Acute lymphoblastic leukemia & 19 & 5 & & 0 & \\
\hline Myelodysplastic syndrome & 13 & 5 & & 1 & \\
\hline Chronic myelogenous leukemia & 19 & 5 & & 3 & \\
\hline \multicolumn{6}{|l|}{ Disease risk at transplant } \\
\hline Standard (CR, CP, RA) & 62 & 21 & \multirow{2}{*}{0.09} & 5 & \multirow{2}{*}{0.58} \\
\hline High (NR, AP, BC, RAEB) & 19 & 2 & & 0 & \\
\hline \multicolumn{6}{|l|}{ Donor sources } \\
\hline Related bone marrow & 36 & 5 & \multirow{4}{*}{0.07} & 1 & \multirow{4}{*}{0.31} \\
\hline Related peripheral blood & 12 & 4 & & 2 & \\
\hline Unrelated bone marrow & 26 & 11 & & 2 & \\
\hline Unrelated cord blood & 7 & 3 & & 0 & \\
\hline \multicolumn{6}{|l|}{ HLA compatibility (except cord blood) } \\
\hline HLA match & 65 & 17 & \multirow{2}{*}{0.46} & 3 & \multirow{2}{*}{0.11} \\
\hline HLA mismatch & 9 & 3 & & 2 & \\
\hline \multicolumn{6}{|l|}{ GVHD prophylaxis } \\
\hline Cyclosporine-based & 54 & 15 & \multirow{3}{*}{0.62} & 3 & \multirow{3}{*}{0.86} \\
\hline Tacrolimus-based & 25 & 8 & & 2 & \\
\hline None & 2 & 0 & & 0 & \\
\hline \multicolumn{6}{|l|}{ Smoking } \\
\hline No & 58 & 16 & \multirow{2}{*}{0.79} & 4 & \multirow{2}{*}{0.56} \\
\hline Yes & 23 & 7 & & 0 & \\
\hline \multicolumn{6}{|l|}{ Prior busulfan (CML) } \\
\hline No & 16 & 4 & 060 & 2 & 042 \\
\hline Yes & 3 & 1 & 0.62 & 1 & 0.42 \\
\hline Abnormal pretransplantion PFT & & & & & \\
\hline No & 73 & 17 & $<000$ & 4 & 041 \\
\hline Yes & 8 & 6 & -0.01 & 1 & 0.41 \\
\hline Acute GVHD & & & & & \\
\hline $0-\mathrm{I}$ & 61 & 17 & 085 & 3 & 036 \\
\hline II-IV & 20 & 6 & 0.05 & 2 & 0.30 \\
\hline Chronic GVHD & & & & & \\
\hline No & 41 & 9 & 020 & 0 & $\leq 0 \Omega 1$ \\
\hline Yes & 40 & 14 & 0.29 & 5 & $<0.01$ \\
\hline
\end{tabular}

CR: complete remission; RA: refractory anemia; CP: chronic phase; NR: non-remission; AP: accelarated phase; BC: blastic phase; refractory anemia with excess blasts; PFT: pulmonary function tests; GVHD: graft-versus-host disease; ${ }^{\#}$ score $\geq 1$ according to NIH consensus criteria; LONIPCs: late-onset noninfectious pulmonary complications. 
more than 5 years after HSCT, with one death each from relapsed leukemia (5.9 years after transplantation), BO (6.3 years), sepsis ( 8.9 years), sudden death (11.5 years), and secondary MDS (11.8 years).

\subsection{Pulmonary Chronic GVHD}

According to NIH consensus criteria for pulmonary chronic GVHD, 23 patients (28\%) had abnormal lung function at some point after transplantation (Table 1). The maximum score for pulmonary GVHD over 5 years was $0,1,2$, and 3 in 58,14 , six, and three patients, respecttively. Among the patients who showed abnormal lung function before transplantation, six developed pulmonary chronic GVHD, which was mild in four patients, moderate in one patient, and severe in one patient. The four patients with mild pulmonary chronic GVHD at 3 months or 1 year after HSCT experienced subsequent recovery to normal pulmonary function by later time points. Univariate analysis of predictors of abnormal lung function following HSCT showed that abnormal pulmonary function tests before transplantation were significantly associated with pulmonary chronic GVHD as defined by NIH criteria $(\mathrm{P}<0.01)$.

\subsection{Changes in Pulmonary Function Tests}

Abnormalities in pulmonary function (FEV1 and/or DLCO $<80 \%$ of predicted) before transplantation were detected in eight patients (10\%). Pretransplant and posttransplant parameters, such as age, gender, disease risk, and smoking, were compared between the eight patients who showed pulmonary dysfunction before transplantation and other patients without pulmonary dysfunction before transplantation. However, there were no predicttive factors that could distinguish between these groups (data not shown). Changes in lung function after HSCT were compared between patients with and without normal pulmonary function test results (Table 2). Abnormal lung function before preconditioning was associated with a decrease in PFTs within 1 year after HSCT, but there was no relationship between abnormal lung function before transplantation and pulmonary dysfunction after 3 or 5 years.

The association between chronic GVHD and serial pulmonary function data is shown in Table $3 . \mathrm{VC} \%$ and FEV $1 \%$ were decreased at 3 and 5 years after HSCT in patients with chronic GVHD. Although DLCO\% was

Table 2. Serial pulmonary function tests in patients with/without pretransplantation abnormality (FEV1 $<80 \%$ or DLCO $<\mathbf{8 0} \%$ predicted).

\begin{tabular}{|c|c|c|c|c|c|c|c|c|c|c|c|}
\hline & $\mathrm{n}$ & Pretransplant (n) & $P$ value & 3 months (n) & $P$ value & 1 year $(n)$ & $P$ value & 3 years (n) & $P$ value & 5 years (n) & $P$ value \\
\hline \multicolumn{12}{|l|}{ VC $\%$} \\
\hline Normal & 73 & $110 \pm 14(73)$ & \multirow{2}{*}{0.13} & $103 \pm 13(65)$ & \multirow{2}{*}{0.05} & $103 \pm 14(63)$ & \multirow{2}{*}{$<0.01$} & $103 \pm 17(62)$ & \multirow{2}{*}{0.59} & $104 \pm 17(62)$ & \multirow{2}{*}{0.74} \\
\hline Abnormal & 8 & $101 \pm 15(8)$ & & $92 \pm 9(7)$ & & $79 \pm 35(7)$ & & $100 \pm 22(7)$ & & $101 \pm 22(8)$ & \\
\hline \multicolumn{12}{|l|}{ FEV1 \% } \\
\hline Normal & 73 & $103 \pm 12(73)$ & \multirow{2}{*}{0.02} & $97 \pm 17(65)$ & \multirow{2}{*}{0.06} & $96 \pm 11(63)$ & \multirow{2}{*}{0.06} & $94 \pm 17(62)$ & \multirow{2}{*}{0.54} & $95 \pm 20(62)$ & \multirow{2}{*}{0.52} \\
\hline Abnormal & 8 & $90 \pm 17(8)$ & & $82 \pm 9(7)$ & & $86 \pm 13(7)$ & & $90 \pm 25(7)$ & & $90 \pm 24(8)$ & \\
\hline \multicolumn{12}{|l|}{ DLCO \% } \\
\hline Normal & 73 & $105 \pm 13(62)$ & \multirow{2}{*}{0.02} & $87 \pm 15(58)$ & \multirow{2}{*}{0.04} & $87 \pm 14(60)$ & \multirow{2}{*}{0.04} & $93 \pm 16(60)$ & \multirow{2}{*}{0.19} & $92 \pm 15(61)$ & \multirow{2}{*}{0.14} \\
\hline Abnormal & 8 & $90 \pm 22(8)$ & & $72 \pm 15(7)$ & & $74 \pm 8(7)$ & & $84 \pm 17(5)$ & & $82 \pm 19(7)$ & \\
\hline
\end{tabular}

Table 3. Serial pulmonary function tests in patients with/without chronic GVHD.

\begin{tabular}{|c|c|c|c|c|c|c|c|c|c|c|c|}
\hline & $\mathrm{n}$ & Pretransplant (n) & $P$ value & 3 months (n) & $P$ value & 1 year $(n)$ & $P$ value & 3 years $(n)$ & $P$ value & 5 years $(n)$ & $P$ value \\
\hline $\mathrm{VC} \%$ & & & & & & & & & & & \\
\hline Chronic GVHD(-) & 41 & $109 \pm 12(41)$ & \multirow{2}{*}{0.97} & $100 \pm 13(38)$ & \multirow{2}{*}{0.87} & $99 \pm 23(37)$ & \multirow{2}{*}{0.81} & $107 \pm 14(35)$ & \multirow{2}{*}{0.05} & $108 \pm 14(34)$ & \multirow{2}{*}{0.02} \\
\hline Chronic GVHD(+) & 40 & $109 \pm 16(40)$ & & $101 \pm 15(34)$ & & $98 \pm 13(34)$ & & $99 \pm 13(34)$ & & $98 \pm 19(36)$ & \\
\hline \multicolumn{12}{|l|}{ FEV1 \% } \\
\hline Chronic GVHD(-) & 41 & $102 \pm 12(41)$ & \multirow{2}{*}{0.67} & $97 \pm 14(38)$ & \multirow{2}{*}{0.28} & $97 \pm 14(37)$ & \multirow{2}{*}{0.06} & $99 \pm 12(35)$ & \multirow{2}{*}{0.02} & $101 \pm 12(34)$ & \multirow{2}{*}{0.01} \\
\hline Chronic GVHD(+) & 40 & $100 \pm 15(40)$ & & $91 \pm 21(34)$ & & $91 \pm 12(34)$ & & $88 \pm 21(34)$ & & $88 \pm 24(36)$ & \\
\hline \multicolumn{12}{|l|}{ DLCO \% } \\
\hline Chronic GVHD(-) & 41 & $98 \pm 14(35)$ & \multirow{2}{*}{0.19} & $86 \pm 14(33)$ & \multirow{2}{*}{0.59} & $87 \pm 14(33)$ & \multirow{2}{*}{0.39} & $92 \pm 15(34)$ & \multirow{2}{*}{0.65} & $91 \pm 16(31)$ & \multirow{2}{*}{0.39} \\
\hline Chronic GVHD(+) & 40 & $103 \pm 16(35)$ & & $83 \pm 15(32)$ & & $83 \pm 14(34)$ & & $90 \pm 19(31)$ & & $87 \pm 15(35)$ & \\
\hline
\end{tabular}


decreased at 3 months and 1 year after HSCT in patients with or without chronic GVHD, there were no differences when comparing the two groups.

\subsection{Late-Onset Pulmonary Complications}

$\mathrm{T}$ Five patients developed late-onset noninfectious pulmonary complications during the observation period. All patients were diagnosed by clinical findings, PFTs, and CT scan. Systemic chronic GVHD was significantly related to such complications $(\mathrm{P}<0.01)$ (Table 1), with $\mathrm{BO}$ occurring in four patients and IP occurring in one patient. The predicted FEV1\% was significantly lower in patients who had late-onset noninfectious pulmonary complications than in those that did not. At 3 or 5 years after HSCT, all lung function parameters differed between patients with or without these complications (Table 4). The characteristics of the patients with late-onset complications are shown in Table 5. All of these patients had extensive chronic GVHD, including mucosal lesions, and two patients were on immunosuppressive therapy. Two patients required home oxygen therapy. One patient with $\mathrm{BO}$ died of respiratory failure at 4.1 years after the onset of pulmonary chronic GVHD.

\section{Discussion}

The present study demonstrated the clinical significance of pulmonary dysfunction in long-term survivors after myeloablative HSCT. Although the incidence of lateonset noninfectious pulmonary complications among patients surviving for 5 years or more after HSCT was relatively low, it was probably influenced by the exclusion of patients who died within 5 years from this analysis. Previous studies of the predictive value of pulmonary function tests for pulmonary complications after transplantation have suggested that poor lung function before transplantation is associated with subsequent pulmonary disease and mortality, as summarized by Chien et al. [15] In the present study, abnormal pretransplantation pulmonary function tests correlated with the risk of early pulmonary dysfunction but not with late-onset pulmonary complications. Savani et al. reported that abnormalities in pretransplantation pulmonary function are useful for predicting the progression of pulmonary dysfunction [9]. They found that pretransplantation FEV1 or DLCO values $<80 \%$ of the predicted level were independently associated with a late decrease in pulmonary function from baseline. Although our results indicated

Table 4. Serial pulmonary function tests in patients with/without late-onset noninfectious pulmonary complications.

\begin{tabular}{|c|c|c|c|c|c|c|c|c|c|c|c|}
\hline & $\mathrm{n}$ & Pretransplant (n) & $P$ value & 3 months (n) & $P$ value & 1 year $(\mathrm{n})$ & $P$ value & 3 years $(n)$ & $P$ value & 5 years $(n)$ & $P$ value \\
\hline $\mathrm{VC} \%$ & & & & & & & & & & & \\
\hline LONIPC(-) & 76 & $109 \pm 13(76)$ & \multirow{2}{*}{0.32} & $101 \pm 12(69)$ & \multirow{2}{*}{0.23} & $99 \pm 18(66)$ & \multirow{2}{*}{0.61} & $106 \pm 11(64)$ & \multirow{2}{*}{$<0.01$} & $107 \pm 13(65)$ & \multirow{2}{*}{$<0.01$} \\
\hline LONIPC(+) & 5 & $115 \pm 20(5)$ & & $111 \pm 18(3)$ & & $94 \pm 14(4)$ & & $73 \pm 14(5)$ & & $67 \pm 15(5)$ & \\
\hline \multicolumn{12}{|l|}{ FEV1 \% } \\
\hline LONIPC(-) & 76 & $102 \pm 12(76)$ & \multirow{2}{*}{0.79} & $102 \pm 12(69)$ & \multirow{2}{*}{0.22} & $96 \pm 11(66)$ & \multirow{2}{*}{0.02} & $98 \pm 10(64)$ & \multirow{2}{*}{$<0.01$} & $100 \pm 12(65)$ & \multirow{2}{*}{$<0.01$} \\
\hline LONIPC(+) & 5 & $103 \pm 24(5)$ & & $103 \pm 24(3)$ & & $82 \pm 17(4)$ & & $48 \pm 15(5)$ & & $45 \pm 17(5)$ & \\
\hline \multicolumn{12}{|l|}{ DLCO \% } \\
\hline LONIPC(-) & 76 & $103 \pm 15(65)$ & \multirow{2}{*}{0.84} & $85 \pm 16(62)$ & \multirow{2}{*}{0.61} & $86 \pm 14(64)$ & \multirow{2}{*}{0.15} & $93 \pm 16(61)$ & \multirow{2}{*}{0.04} & $92 \pm 15(62)$ & \multirow{2}{*}{0.03} \\
\hline LONIPC $(+)$ & 5 & $104 \pm 16(5)$ & & $80 \pm 18(3)$ & & $73 \pm 7(3)$ & & $76 \pm 22(4)$ & & $75 \pm 18(5)$ & \\
\hline
\end{tabular}

LONIPCs: late-onset noninfectious pulmonary complications.

Table 5. Clinical characteristics of patients with late-onset noninfectious pulmonary complications.

\begin{tabular}{|c|c|c|c|c|c|c|c|c|c|c|c|c|c|}
\hline \multirow{2}{*}{ No. } & \multirow{2}{*}{ Age } & \multirow{2}{*}{ Sex } & \multirow{2}{*}{ Diagnosis } & \multirow{2}{*}{ Busulfan } & \multirow{2}{*}{ Smoking } & \multirow{2}{*}{$\begin{array}{c}\text { Pretransplantion } \\
\text { PFT }\end{array}$} & \multirow{2}{*}{$\begin{array}{l}\text { Acute } \\
\text { GVHD }\end{array}$} & \multirow{2}{*}{$\begin{array}{c}\text { Sites of chronic GVHD } \\
\text { Other than lung }\end{array}$} & \multicolumn{4}{|c|}{ Pulmonary score $^{\#}$} & \multirow{2}{*}{ Complication } \\
\hline & & & & & & & & & 3 mon. & $1 \mathrm{y}$ & $3 y$ & $5 \mathrm{y}$ & \\
\hline 1 & 21 & $\mathrm{~F}$ & CML & Yes & $\mathrm{N}$ & Abnormal & I & Extensive (skin, mouth) & 0 & 1 & 3 & 3 & $\mathrm{BO}$ \\
\hline 2 & 53 & $\mathrm{~F}$ & CML & No & $\mathrm{N}$ & Normal & II & Extensive (skin, mouth, liver) & 0 & 0 & 2 & 3 & $\mathrm{BO}$ \\
\hline 3 & 52 & $\mathrm{~F}$ & MDS & No & $\mathrm{N}$ & Normal & I & extensive (skin, mouth) & 1 & 1 & 2 & 1 & IP \\
\hline 4 & 30 & $\mathrm{M}$ & CML & No & $\mathrm{Y}$ & Normal & III & Extensive (mouth, liver) & 0 & 1 & 2 & 2 & $\mathrm{BO}$ \\
\hline 5 & 36 & $\mathrm{~F}$ & AML & No & $\mathrm{N}$ & Normal & III & Extensive (mouth, intestine) & 0 & 0 & 3 & 3 & $\mathrm{BO}$ \\
\hline
\end{tabular}

CML: chronic myelogenous leukemia; MDS: myelodysplastic syndrome; AML: acute myelogenous leukemia; PFT: pulmonary function tests; GVHD:

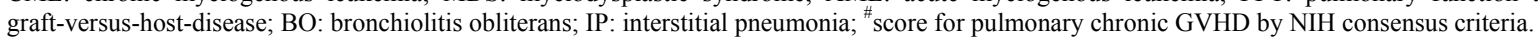


that pretransplantation pulmonary function test could not predict abnormal lung function in the late period after HSCT, there was a relationship between impaired pulmonary function before transplantation and the occurrence of pulmonary chronic GVHD (diagnosed according to NIH criteria). Of six patients with pulmonary chronic GVHD who had abnormal pulmonary function tests before transplantation, three patients showed a decline of lung function within 1 year after HSCT. The discrepancy between the incidence of abnormal posttransplantation lung function and pulmonary chronic GVHD in patients with abnormal pretransplantation pulmonary function tests can be explained by the timing of the onset of pulmonary dysfunction.

As shown in Table 4, all patients who developed longterm pulmonary complications had at least moderately abnormal pulmonary function during the late phase. These patients were not distinguishable from the other patients who developed pulmonary chronic GVHD within 1 year but did not go on to show long-term complications. Most patients who developed long-term complications were diagnosed with them within 3 months to 1 year after transplantation [2-4]. The present study suggested that a subgroup of the patients who are asymptomatic at 1 year after HSCT may eventually develop longterm complications. These patients had only a slight decline of FEV1\% at 1 year. Previous studies have shown that chronic GVHD is the most powerful predictor of late-onset noninfectious pulmonary complications [2-4], and that chronic GVHD involving the mucosa is more likely to be associated with such complications $[2,16]$. In agreement with previous reports, all patients with lateonset complications in the present study had experienced extensive chronic GVHD, including sicca syndrome.

The present study had several limitations. For example, it was difficult to obtain follow-up pulmonary function on all patients over the long follow-up period. The retrospective nature, small sample size, and the exclusion of patients who died with within 5 years post transplantation may have biased the results. Therefore, the results of pulmonary function tests for prediction of late pulmonary complications should be interpreted with caution.

In conclusion, these data demonstrate that abnormal lung function before transplantation may be associated with a decline in pulmonary function within 1 year after HSCT, but did not have predictive significance for longterm noninfectious pulmonary complications in patients surviving for $\geq 5$ years after HSCT. Patients with extensive chronic GVHD and mucosal lesions had the highest risk of developing long-term pulmonary complications and should undergo monitoring by serial pulmonary function tests to detect such complications, even if their lung function is normal before transplantation. Further studies should focus on validation of these results and to determine if early intervention using inhaled corticosteroids [17], macrolides [18], or montelukast [19] might be beneficial to ameliorate early disease.

\section{Acknowledgements}

This work was supported by a grant from Kanagawa Health Foundation.

\section{REFERENCES}

[1] A. O. Soubani, K. B. Miller and P. M. Hassoun, "Pulmonary Complications of Bone Marrow Transplantation," Chest, Vol. 109, No. 4, 1996, pp. 1066-1077. doi:10.1378/chest.109.4.1066

[2] E. Sakaida, C. Nakaseko, A. Harima, A. Yokota, R. Cho, Y. Saito, et al., "Late-Onset Noninfectious Pulmonary Complications after Allogeneic Stem Cell Transplantation are Significantly Associated with Chronic Graft-versusHost Disease and with the Graft-versus-Leukemia Effect," Blood, Vol. 102, No. 12, 2003, pp. 4236-4242. doi:10.1182/blood-2002-10-3289

[3] A. Palmas, A. Tefferi, J. L. Myers, J. P. Scott, S. J. Swensen, M. G. Chen, et al., "Late-Onset Noninfectious Pulmonary Complications after Allogeneic Bone Marrow Transplantation," British Journal of Haematology, Vol. 100, No. 4, 1998, pp. 680-687. doi:10.1046/j.1365-2141.1998.00617.x

[4] F. Patriarca, C. Skert, A. Sperotto, D. Damiani, M. Cerno, A. Geromin, et al., "Incidence, Outcome, and Risk Factors of Late-Onset Noninfectious Pulmonary Complications after Unrelated Donor Stem Cell Transplantation," Bone Marrow Transplant, Vol. 33, No. 7, 2004, pp. 751758. doi:10.1038/sj.bmt.1704426

[5] E. M. Gore, C. A. Lawton, R. C. Ash and R. J. Lipchik, "Pulmonary Function Changes in Long-Term Survivors of Bone Marrow Transplantation," International Journal of Radiation Oncology, Biology, Physics, Vol. 36, No. 1, 1996, pp. 67-75. doi:10.1016/S0360-3016(96)00123-X

[6] P. Fulgoni, M. C. Zoia, A. Corsico, M. Beccaria, G. Georgiani, G. Bossi, et al., "Lung Function in Survivors of Childhood Acute Lymphoblastic Leukemia," Chest, Vol. 116, No. 5, 1999, pp. 1163-1167. doi:10.1378/chest.116.5.1163

[7] T. K. Marras, C. K. Chan, J. H. Lipton, H. A. Messner, J. P. Szalai and A. Laupacis, "Long-Term Pulmonary Function Abnormalities and Survival after Allogeneic Marrow Transplantation," Bone Marrow Transplant, Vol. 33, No. 5, 2004, pp. 509-517. doi:10.1038/sj.bmt.1704377

[8] B. N. Savani, A. Montero, C. Wu, N. Nlonda, E. Read, C. Dunbar, et al., "Prediction and Prevention of TransplantRelated Mortality from Pulmonary Causes after Total Body Irradiation and Allogeneic Stem Cell Transplantation," Biology of Blood and Marrow Transplantation, Vol. 11, No. 3, 2005, pp. 223-230. doi:10.1016/j.bbmt.2004.12.328

[9] B. N. Savani, A. Montero, R. Srinivasan, A. Singh, A. 
Shenoy, S. Mielke, et al., "Chronic GVHD and Pretransplantation Abnormalities in Pulmonary Function Are the Main Determinants Predicting Worsening Pulmonary Function in Long-Term Survivors after Stem Cell Transplantation," Biology of Blood and Marrow Transplantation, Vol. 12, No. 12, 2006, pp. 1261-1269.

doi:10.1016/j.bbmt.2006.07.016

[10] B. P. Soule, N. L. Simone, B. N. Savani, H. Ning, P. S. Albert, A. J. Barrett, et al., "Pulmonary Function Following Total Body Irradiation (with or without Lung Shielding) and Allogeneic Peripheral Blood Stem Cell Transplant," Bone Marrow Transplant, Vol. 40, No. 6, 2007, pp. 573-578. doi:10.1038/sj.bmt.1705771

[11] K. Fujimaki, J. Taguchi, H. Fujita, M. Hattori, E. Yamazaki, N. Takahashi, et al., "Thiotepa/Cyclophosphamide/ TBI as a Conditioning Regimen for Allogeneic Hematopoietic Stem Cell Transplantation in Patients with Myelodysplastic Syndrome," Bone Marrow Transplant, Vol. 33, No. 8, 2004, pp. 789-792. doi:10.1038/sj.bmt.1704451

[12] A. H. Filipovich, D. Weisdorf, S. Pavletic, G. Socie, J. R. Wingard, S. J. Lee, et al., "National Institutes of Health Consensus Development Project on Criteria for Clinical Trials in Chronic Graft-versus-Host Disease: I. Diagnosis and Staging Working Group Report," Biology of Blood and Marrow Transplantation, Vol. 11, No. 12, 2005, pp. 945-956. doi:10.1016/j.bbmt.2005.09.004

[13] D. Przepiorka, D. Weisdorf, P. Martin, H. G. Klingemann, P. Beatty, J. Hows, et al., "1994 Consensus Conference on Acute GVHD Grading," Bone Marrow Transplant, Vol. 15, No. 6, 1995, pp. 825-828.

[14] H. M. Shulman, K. M. Sullivan, P. L. Weiden, G. B. Mc-

\section{Abbreviations}

BO: bronchiolitis obliterans;

CML: chronic myelogenous leukemia;

CR: complete remission;

CT: computed tomography;

DLCO: diffusion capacity of carbon monoxide;

FEV1: forced expiratory volume in one second;

FVC: forced vital capacity;

GVHD: graft-versus-host disease;
Donald, G. E. Striker, G. E. Sale, et al., "Chronic Graftversus-Host Syndrome in Man. A Long-Term Clinicopathologic Study of 20 Seattle Patients," The American Journal of Medicine, Vol. 69, No. 2, 1980, pp. 204-217. doi:10.1016/0002-9343(80)90380-0

[15] J. W. Chien, D. K. Madtes and J. G. Clark, "Pulmonary Function Testing Prior to Hematopoietic Stem Cell Transplantation," Bone Marrow Transplant, Vol. 35, No. 5, 2005, pp. 429-435. doi:10.1038/sj.bmt.1704783

[16] F. Patriarca, V. Poletti, U. Costabel, M. L. Battista, A. Sperotto, M. Medeot, et al., "Clinical Presentation, Outcome and Risk Factors of Late-Onset Non-Infectious Pulmonary Complications after Allogeneic Stem Cell Transplantation," Current Stem Cell Research \& Therapy, Vol. 4, No. 2, 2009, pp. 161-167. doi: $10.2174 / 157488809788167436$

[17] L. Bashoura, S. Gupta, A. Jain, D. R. Couriel, K. V. Komanduri, G. A. Eapen, et al., "Inhaled Corticosteroids Stabilize Constrictive Bronchiolitis after Hematopoietic Stem Cell Transplantation," Bone Marrow Transplant, Vol. 41, No. 1, 2008, pp. 63-67. doi:10.1038/sj.bmt.1705877

[18] N. Maimon, J. H. Lipton, C. K. Chan and T. K. Marras, "Macrolides in the Treatment of Bronchiolitis Obliterans in Allograft Recipients," Bone Marrow Transplant, Vol. 44, No. 2, 2009, pp. 69-73. doi:10.1038/bmt.2009.106

[19] R. Or, B. Gesundheit, I. Resnick, M. Bitan, A. Avraham, M. Avgil, et al., "Sparing Effect by Montelukast Treatment for Chronic Graft versus Host Disease: A Pilot Study," Transplantation, Vol. 83, No. 5, 2007, pp. 577-581. doi:10.1097/01.tp.0000255575.03795.df

HSCT: hematopoietic stem cell transplantation;

IP: interstitial pneumonia;

LFS: lung function score;

MDS: myelodysplastic syndrome;

MTX: methotrexate;

NIH: national institutes of health;

PFTs: pulmonary function tests;

RAEB: refractory anemia with excess blast;

VC: vital capacity. 